\title{
Elicitation the Criteria of Scenography to enhance the effectiveness of windows display design
}

\author{
Sara Ahmed Sayed Ali \\ Lecturer, Graphics and media arts department - Faculty of arts and design - October University for Modern Sciences and Arts -Egypt
}

\section{KEY WORDS:}

Scenography, Hologram, optical illusion, Semiotic, Nostalgia

\begin{abstract}
:
Scenography is the place where the theatre or cinema shows are displayed including furniture, auditory and visual or humanity elements, it is the art where a good integration between scenic design elements is accrued to deliver the idea or the dramatic event to the audience in admirable and thrilling ways. Scenography has a much closed relationship with windows display design because of the usage of the same elements to offer the products or services to the target audience in attractive and thrilling ways through using thesignificances of those elements to relate the offered products or services with feelings and specific meanings.

While seeing windows display designs we noticed that there is lack of applying the appropriate principles of scenic designs sometimes there is no relationship between the visual elements that are used and itssignificances From that point the problem of the research appeared and the researcher summarized it in the following questions: How the benefits of the significances of the elements used in scenic designs for windows display can be used to enhance the mental image of the products and services, What are the criteria of designing the scenic designs for windows display to motivate a positive feelings to the recipients to increase itseffectiveness.

The aim of the research was to study the scenography art and its elements and how to get the benefits of thesignificances to relate them with the products or services, and to put a criteria to design the scenic designs for windows display.

The research followed the descriptive analytical study to describe and analysis a samples of contemporary windows display designs, qualitative approach to measure the impact of scenography in window display on the recipients through a questionnaire to elicit the criteria of designing a scenic designs for windows display.

The results of the research showed that when getting the benefits of the significances of the elements used to design the scenic designs for windows display and when following the appropriate criteria to design it thescenic designs of the windows display will be more enhanced and effective on the recipients.
\end{abstract}




\section{INTRODUCTION:}

In the face of intense competition, creativity and innovation have become the main engine to judge the progression of countries. Hence using a creative strategies for advertising design became a must to support and develop the national market through concentrating on a core element which is using the art of scenography in advertising to add value to the products and services, And because windows display designs consider as one of the most important means of advertising it became very important to pay attention to them to add some kind of creativity and innovation on its design.

\section{Literature Review}

Scenography as a term is not a new term it was appeared in the architecture of the Renaissance, and the Greeks and Romanshas used it before, Scenography as a term has been derived from theGreek word (Skenegraphia) which means the decoration of the facade of the theater and taking the context of the drama into consideration, It is the spatial environment of the theater including platforms, scenery elements, lighting, music and special effects.

Scenography is the art of coordinating the theatrical space and control its form in order to achieve the objectives of the theatrical presentation(Lamia A. Karim, 2006).

It is a depiction of the theater space and its formation through the furnishing with a range of audio-visual effects in order to clarify the meanings of the dramatic context it includes all the material and human elements in the theater space from decoration, furniture and accessories, in addition to the movement of humans and physical elements.

Technological development has led to the development of the art of scenography, where the use of advanced techniques of sound and lights, which provided a variety of sound and light effects in addition to the techniques of projection, laser, and hologram, which made this art has the ability to excite the recipients visually and dazzle them in a way that attract their attention. (Walid Fayez ,2012)

\subsection{Definition of Scenography in advertising}

It is the art of organizingthe space allocated to the ad, with all its dimensions in a way that organize all the elements of design aesthetically to achieve the communication functions of the advertisement in way that can have a positive impact on the recipients easily and with minimal effort, through the development of appropriate visual solutions to coordinate the space to make it comfortable and distinctive in all aesthetic conditions and standards.

Scenography in advertising is the planning and innovation to exploit the advertising space by combining the components of the scenic design and how to distribute and coordinate them based on architectural and structural data, it is also a wide awareness of all the internal elements in the design of advertising in the space according to its purpose.

\subsection{Scenography in windows display design}

The screening scenarios are used in the theater scene to form a cinematic scene that is suitable for displaying a product or service by employing lighting, colors, visual tricks, display screens or even modern techniques of scenography such as hologram or augmented reality to influence the recipients and to link the product with visual indications carried by the elements of the scene to leave Positive effect on the same recipient towards the products or services offered during the display windows(Lamia A. Karim, 2006(

The researcher has developed a set of procedural definitions of the scenography in windows display design as follows:

- It's the coordination and integration between the visual elements like lighting, colors, visual effects and physical elements which may include elements similar to human elements such as mannequin, animals or any other elements to express the product or service by linking those products with the connotations of elements used in windows display design to evoke certain feelings and to leave a positive impact on the receivers toward the offered products or services.

- It's the visual planning to make the good integration between the visual elements used to design the scenic design for windows display which may include lighting, colors and modern techniques in the field of scenography such as hologram, projection or even augmented reality, in addition to the physical elements that may use its connotations to link it with the offered products or 
servicesto evoke a positive feelings and to build a certain mental image to the receivers towards the products or services.

2. The Main roles of scenography in windows display design

There are a lots of functions and roles played by the art of scenography when linked with windows display design which can be summarized in the following points:

2.1 Organize the space of the window display: By applying the principles of scenography, the space of the window display can be more suitabletofocus on the different elements and evoke the integration between them to enhance its visibility and to help in linking between those elements and its significances to leave a positive image about the products or services

2.2 Designing the art compositions that adding distinctiveness to the window display: the art of scenography is concerned with studying how the elements of theatrical or cinematic scenes are arranged It include the foundations for putting the pieces of decoration and furniture, the way the actors stand, their costumes and illuminations and how to use it to integrate with the colors and sound effects, which makes the application of the principles of this art in windows display design add some kind of excellence and ability to impress the receivers.

2.3 Enhancing the imagination and creativity for windows display design:Scenography provides the foundations and principles that followed in the design of theatrical or cinematic scenes in addition to creativity and innovationhence it will add uniqueness and creativity to windows display designs as well.

2.4 Expressing visual connotations and concepts that enhance the image of the product or service: Through the art of scenography and the application of its foundations and principles a scenic designs for cinema and theatre with different and special concepts can be applied, There are plays for children which designed with certain principlesthat differs from historical plays and when applying the principles of scenography in windows display designs it will add a certain connotations that will be linked with the products or services in a way that will make the receiver think about the product or service from certain perspective.

2-5 creating a distinctive visual state: The art of scenography creates a distinctive visual state that affects all the senses of the receiver which adds to the windows displays the ability to grab the attention (Nicoleta,2009)

\section{The Main components of scenography in} windows display design

The Scenic design for windows display consists of the following components

- A space with accurate and specified dimensions. - Visual elements like lighting, Visual effects, clothing, and other physical elements that express the product or service.

- A pre-prepared plan to furnish the windowdisplay's space with the visual elements in a way that can be integrated with the product if they are among those elements to influence positivelyon the recipients(Walid Fayez ,2012)

The visual elements used to design the scenic design for windows display and the role of each element will be covered as follows:

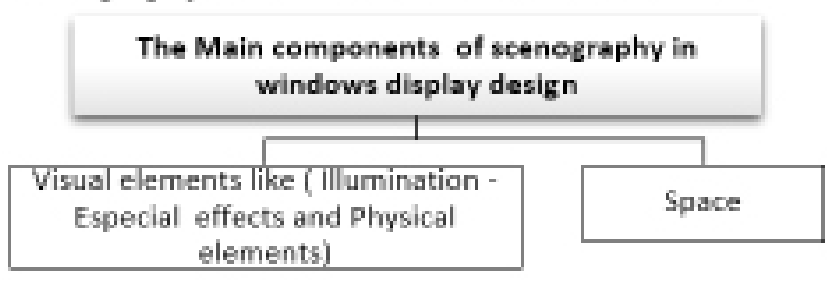

Diagram (1) The Main components of scenography in windows display design

3.1Illumination: Theatrical lighting first appeared in what is known as "Spot Light" in 1911 and now, with the development of technology, there are tremendous possibilities for lighting the scenic designs in all colors and lighting effects, which can be changed in a matter of seconds to other effects and illumination, which gives the theater scene a kind of visual dazzling for the recipients, as we can see in the following scenes from the play Beetlejuice Figure (1) 

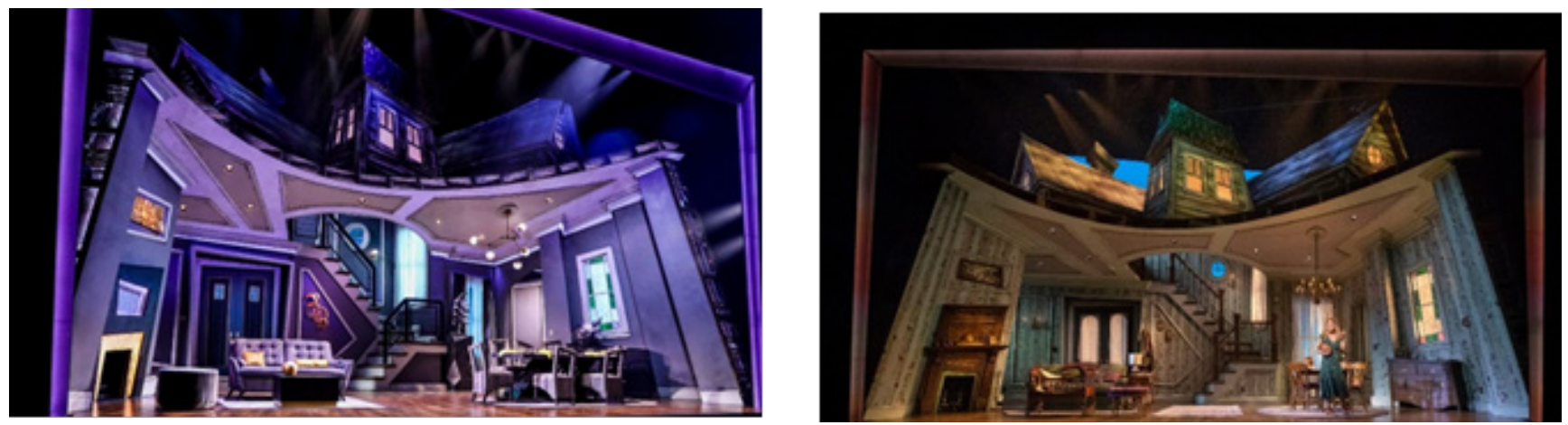

Fig (1)The role of illumination and lighting effects in changing the general atmosphere of the play in a matter of seconds, and moving the recipient from events to events in an impressive way

\subsubsection{Main forms of illumination in the scenic design of windows display:}

Direct illumination: which is clearly characterized by its source, It isdirected to focus on the important element in the windows display and often this element is the product advertised to draw the attention of the recipient toward it, and if the purpose of the window display is to link the product or service with the connotations of another element then the Lighting will be focused on this element, as we can see in figure (2) where we find the lighting focuses on the cake wherethe product "The bag" is located on the top of this cake, like a cherry which indicate thatthis bag will add beauty and elegance to your outfit just like the cherries that add beauty to the cake.

Indirect illumination: which is haven't an obvious source It has less illumination than the direct one ,It is often used to give aesthetics and colors of light through the window display to attract the receiver's attention and to create a state of visual dazzling. (John Munro,2019)

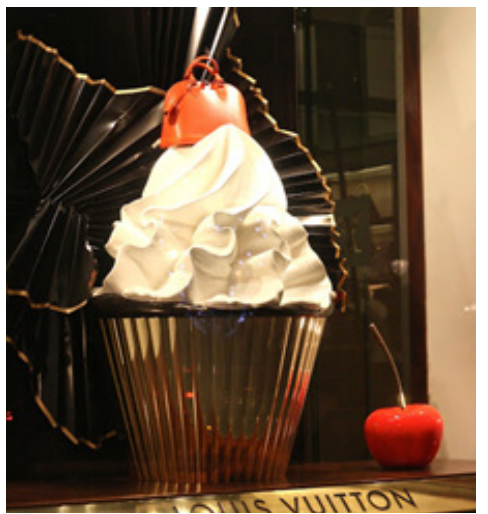

Fig (2) direct lighting and its role in grabbing the attention to the product
Lighting effects: depend on the different distribution of lighting, intensity and its amountin a specific period of time Itis used in the windows display to attract attention and to give a kind of innovation to the design as we can see in figure (3) where the use of spotlights distributed around the product where Some lights are illuminated and others are switched off quickly and suddenly, which grab the attention of the receiver toward the product.

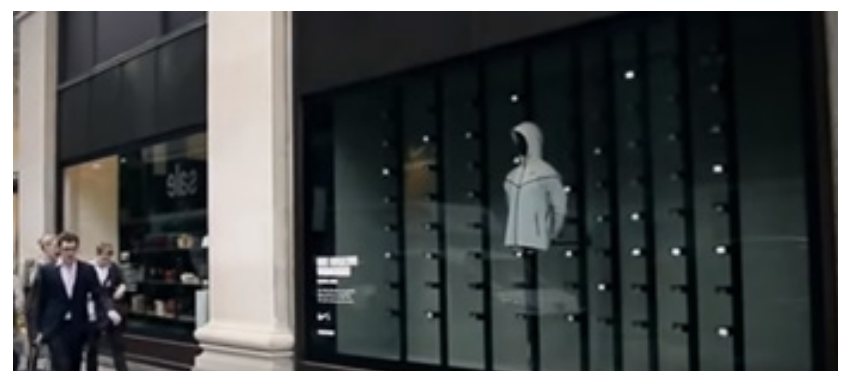

Fig (3) Using the lighting effects in the window display around the product to grab the attention

3.2 Tricks and effects:Because of the technological development, many tricks and influences have emerged in scenography, whether in theatrical or cinematic scenes. Visual tricks and effects are used according to the dramatic context of the play or the movie scene, through the use of light effects, shadows, color switching and hologram-based presentations. Tricks and effects are used to influence on all the senses of the recipient and persuade him withillusionary dramatic events that may seem to be superstitious or legendary and it may be used to add certain effects to create a certain atmospherelike rain, sky or fire. 


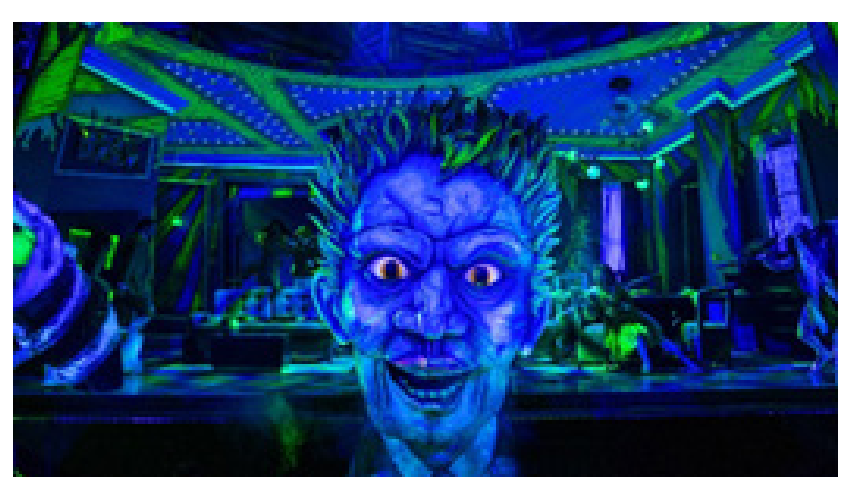

Fig (4) The usage of hologram in the scenography as a visual effect to grab the audience attention

\subsubsection{Main visual tricks and effects in the scenic de- sign of windows display: \\ Visual tricks and effects can be used to design the sce- nic designs of windows display to add uniqueness and innovation, they often include holograms and visual tricks.}

-Hologram is a three-dimensional imaging using lasers by combining two beams of lasers to scan the object to be photographed, and then using those rays to produce three-dimensional holographic image of the same element with a very high quality and it can be colored and animated (Shimaa,2019), Hologram was used in the windows display to add interactivity and suspense in order to grab the recipient's attention to them, as we can see in the following sample (Figure 5) where the holographic image of the product moves and changes its colors once the recipient interacts with the window display even if the store is closed which creates a new interactive experience between the recipient and the design of the window display.

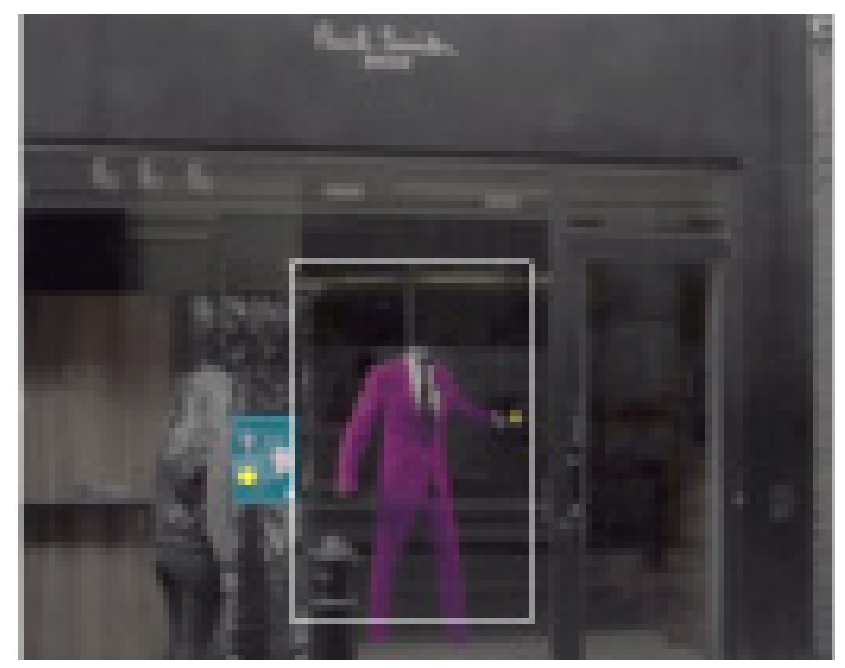

Figure (5) Using hologram technology in the window display that creates a new interactive experience
- Optical illusion is considered as one of the artistic directions that depends on showing the visual elements in a form that deludes the eye and shows the visual elements in a different way from its look in reality,Optical illusion has appeared in some theatrical scenes to delude the eye with depth or movement, and it can be implemented through using geometric shapes with sharp edges such as rectangular square and overlapping circles and fine lines or using strong contrast between colors or between black and white, as we can see in figure (6)Hanan,2016)

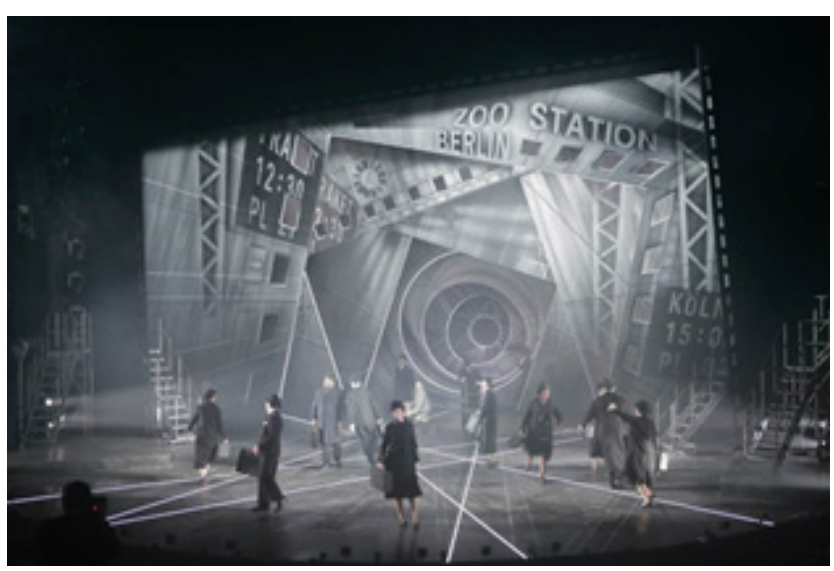

Figure (6) The usage of optical illusions in theatrical plays to add a sense of depth and movement

The art of optical illusion is used in some of the windows display to attract the recipient's attention towards the product in a strangeness and uniqueness wayIn the window displayshown in figure (7) a crossed geometric lines were used with curved lines in a system that gives a sense of depth and force the eyes to pay attention to the product in the middle of the design, The researcherassume that the usage of visual deception through optical illusion in designing the scenic designs of windows display may cause distraction and inability to see the product if it was applied with unthinkable manner, which the researcher will try to measure through the quantitative approaches.
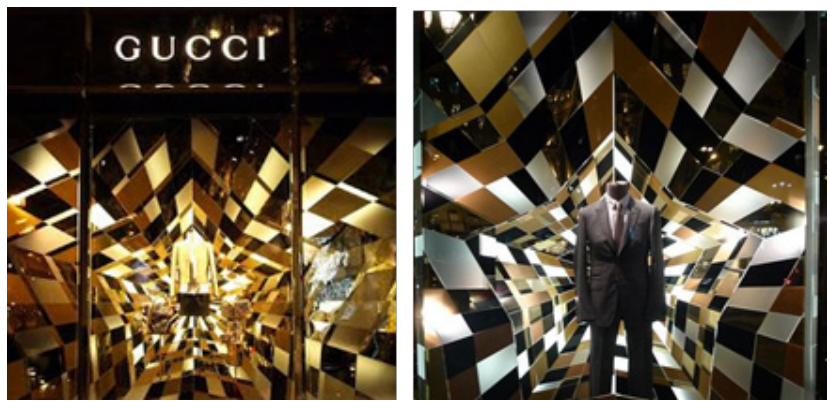

Figure (7) the usage of optical illusions in the windows display to add a sense of movement and depth and to focus on the product 
4. Sciences and concepts related to Scenography and its relation to windows display

There are many sciences and concepts associated with the art of scenography, which integrated within the scope of its design to design theatrical or cinematic scenes that carry a positive impact toward the receiver. Diagram (2) shows the most prominent of those sciences and concepts

4.1 Semiotic: Is the study of the meaning is the scientific study of symbols as communication tools It covers how to use symbols and signs as means of communication in a language, as well as the relationship between the symbol and what it indicates. It concern with all communication systems that are made through signals, signs or symbols(Derbovena,n, Roeckb, Verstraetea,2012)

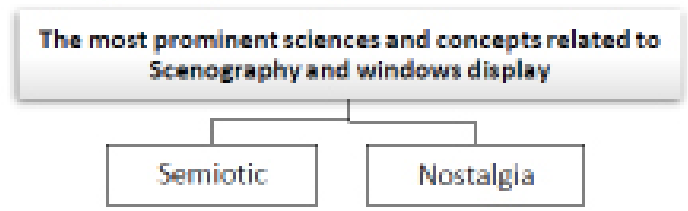

Diagram (2) the most prominent sciences and concepts related to Scenography and windows display

\subsubsection{The Elements of semiotics in scenic designs for windows display:}

Semiotics in scenography is divided into three basic elements, illustrated in Diagram(3)

Syntacticsindicates the physical elements that exist within the scenic designs of the windows dispaly, which draws the attention of the recipient when seeing them, they are the elements as they are which stripped of their significance.

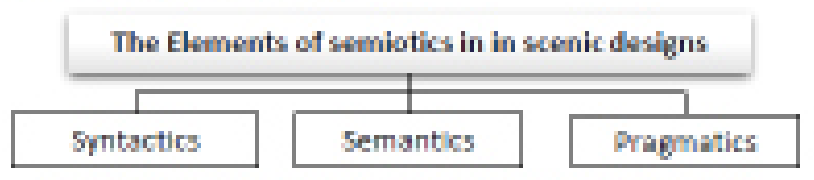

Diagram (3)The Elements of semiotics in scenic designs for windows display

Semanticsrefers to the indications of the elements used in the scenic designs of the windows display, It signifies the visual metaphore from using those elemets, as we can see in figure (8) where the hat was used and placed as a back of the tortoise to signify that that hat will protect the head as the tortoise protects itself and from here the product has acquired meaning and significance from the elements that was used in the scenic design for this window display.

Pragmatics: indicates the main objective of the win- dow display, which the advertiser wants to deliver to the recipient(Rankin,2016).

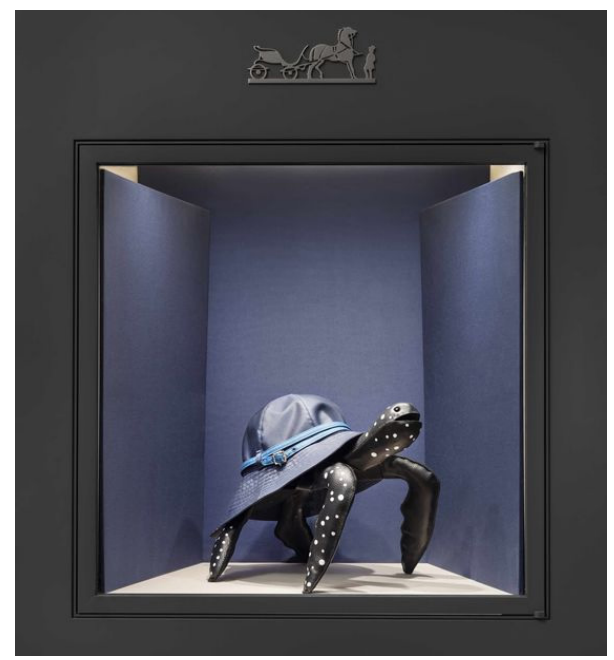

Figure (8) Using visual elements to link its significance to the product to give it related meanings

The researcher's point of view is the designer thinks about pragmatics at the beginning and then begins to think about the visual elements that will be usedin the scenic designs of the windows display designthrough getting the benefits from its significances to impact on the recipient and to relate between the products with the significances of those elements to achieve the main objective, which is often persuade the recipient to buy the offered commodities through the windows display While the recipient thinks about the opposite, he first thinks about the syntactic, which is the elements that were used in the scenic designs of the windows display, which may raise some questions about the significance of those elements, and therefore, by observing the rest of the elements used in the design, the recipient will understand the significances of the used elementshence the main goal of the design which is pragmatic will be achieved, the research illustrated diagram (4) to clarify the relationship between the elements of semiotics in the scenic designs of windows display.

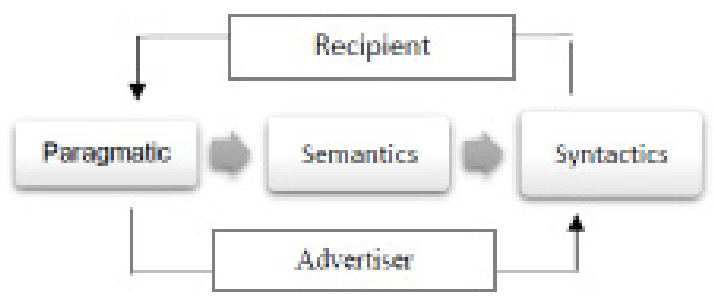

Diagram (4) the relationship between the elements of semiotics in the scenic designs of windows display and the relationship between the recipient and the advertiser 
4.2 Nostalgia: It is the desire to return to the past with its memories it is a type of human feeling that may aperson feel while remembering the past through listening to a certain music that he heard in his childhood, thus he feels a desire to return to this past; nostalgia may also be known as the desire to return to childhood It's the uncomfortable feeling due to the lack of people or things that a person is familiar with and longing for the existence in his life (J. Hartmanna, H. Brunk,2019). nostalgia has been used as a direction in designing many theatrical and cinematic scenes in order to

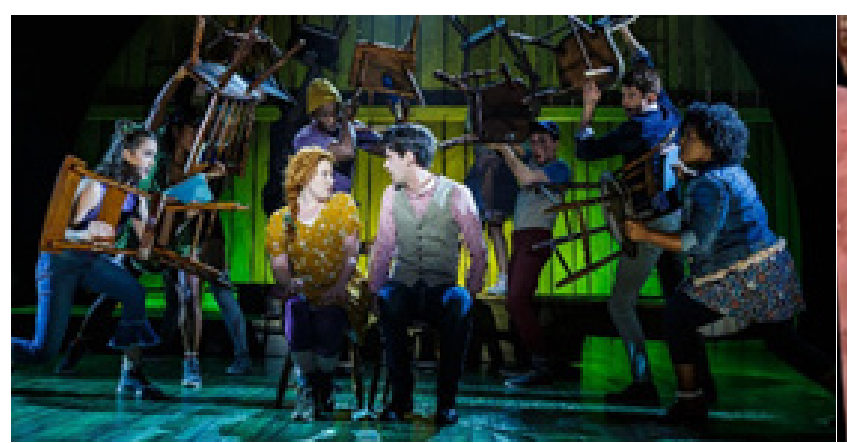

Figure (9) The usage of nostalgia in designing the scenic design of the play satisfy the desire of the recipient In returning to the atmosphere of the past in Figure (9) where the idea of nostalgia was used in designing the scenic design of the show as it is adapted from an old novel which makes the recipient live the events of that novel and recalls memories.

The researcher sees that the nostalgia also usedin the scenic designs of the windows display, to make the recipient link the commodity or service with certain memories which contributes to leave a positive impression on the recipient that persuade him to buy the commodities, Figure (10)

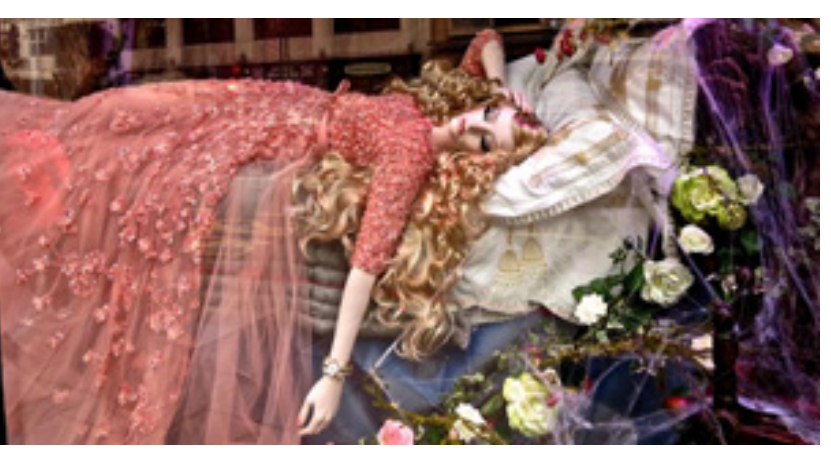

Figure (10) Using the nostalgia in designing the windows display, depending on the story of the sleeping princess

\section{Analytical study of samples of windows display}

The researcher will analyze below samples of windows display to study the elements used their significance and their effect on the recipient as follows:

\subsection{Sample 1}

\begin{tabular}{|l|l|}
\hline \multicolumn{2}{|c|}{ 5.1.1 Description } \\
\hline \multicolumn{2}{|c|}{ Data related to the window display } \\
\hline Store Name & Christian Louboutin \\
\hline Store activity & Sell feminine bags and shoes \\
\hline Store Place & Harrods, UK \\
\hline Date & January 2012 \\
\hline
\end{tabular}
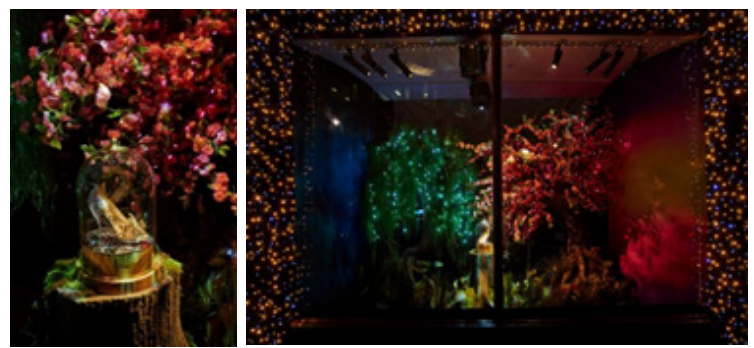

Figure (11) Christian Louboutin shoe

\begin{tabular}{|l|l|}
\hline \multicolumn{2}{|l|}{5.1 .2 Analysis } \\
\hline Visual elements & $\begin{array}{l}\text { Only one element was used, a shoe called a Cinderella shoe, it was placed inside a clear glass box, a } \\
\text { large amount of roses and trees was used to add a dreamy touch to the design and to link this design } \\
\text { to the Cinderella film. A slight light effects were used throughout the design on the trees and roses in } \\
\text { addition to strong lighting directed directly to the shoe to focus on it, lighting was used in different } \\
\text { colors to create a distinctive atmosphere for the window display. }\end{array}$ \\
\hline Semiotic & $\begin{array}{l}\text { By relying on one element the shoe that bears the name "Cinderella", the product gained signifi- } \\
\text { cances from Cinderella's shoewhich indicating that the products of this store are all unique and } \\
\text { whoever wears one of these shoes, will become like Cinderella in her beauty }\end{array}$ \\
\hline
\end{tabular}




\begin{tabular}{|l|l|}
\hline Nostalgia & $\begin{array}{l}\text { By seeing the shoe and knowing its name, recipient will remember Cinderella's movie and her ap- } \\
\text { pearance while wearing the shoe, hence the recipient will believe that obtaining this shoe will bring } \\
\text { back beautiful memories. }\end{array}$ \\
\hline $\begin{array}{l}\text { 5.1.3 Research- } \\
\text { er's Suggestions } \\
\text { to develop the } \\
\text { window display }\end{array}$ & $\begin{array}{l}\text { - it is possible to put a model for Cinderella along with the design elements by focusing on the shoe } \\
\text { in order to support the idea } \\
\text { - Use a backgrounds from the film to enrich the design and to achieve more correlation between the }\end{array}$ \\
\hline
\end{tabular}

\subsection{Sample 2}

\begin{tabular}{|l|l|}
\hline \multicolumn{2}{|c|}{ D.2.1 Description } \\
\hline \multicolumn{2}{|c|}{ Data related to the window display } \\
\hline Store Name & Gato Store \\
\hline Store activity & Sell feminine bags and shoes \\
\hline Store Place & Argentina \\
\hline Date & Jannary 2012 \\
\hline
\end{tabular}

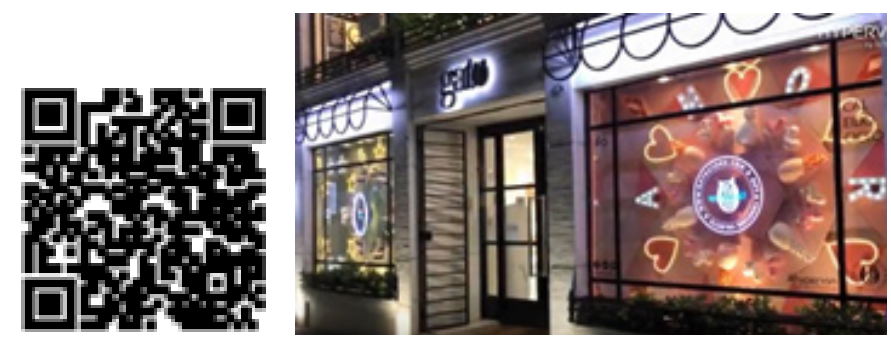

Figure (12) Gato store for home

\subsubsection{Analysis}

\begin{tabular}{|l|l|}
\hline Visual elements & $\begin{array}{l}\text { Animated images of the products in a clockwise direction around a holographic image were used } \\
\text { in this window display which grab the recipient's attention greatly towards the window due to its } \\
\text { uniqueness and dazzle. }\end{array}$ \\
\hline Semiotic & $\begin{array}{l}\text { The window was distinguished by the usage of animated holographic images. Warm colors were } \\
\text { used in one of the sides of the display window in addition to the heart symbol, in an indication that } \\
\text { the products of this store will add warmth and love to the house while on the other side of the window } \\
\text { a symbols of stars that matched were added which are suitable to the nature of the products that was } \\
\text { shown on this side where audio players were shown in an indication that these products will a festive } \\
\text { spirit to your home. }\end{array}$ \\
\hline $\begin{array}{l}\text { 5-1-3 Research- } \\
\text { er's proposals } \\
\text { to develop the } \\
\text { display window }\end{array}$ & $\begin{array}{l}\text { It is possible to add an interactivity between the holographic images and the recipient by using the } \\
\text { sense of touch through changing the displayed images by simple touchwhich may create a new in- } \\
\text { teractive experience with the window that would support the relationship between the recipient and } \\
\text { the brand. }\end{array}$ \\
\hline
\end{tabular}

\section{Methodology}

The research followed the qualitative approach to elicit the criteria of designing the scenic design for windows displaythrough designing a questionnaire form and distributed it to 50 persons to measure

1- The impact of using a diversity of scenic design elements in windows display on grabbing the attention of the recipients and motivate them to enter the stores.

2- How the recipients understand the significances of the elements used.
3- The positive impact of the scenic designs of windows display on the decision of purchasing.

\subsection{Characteristics of the chosen participants:}

- Average age from 20 to 60 years oldSocial level is from B to A Class

- The educational background of the participants is in interior and advertising designs.

A three samples of windows display were chosen they are different in the way of using the visual elements and effects, the questions and the results of the questionnaire were as follows: 


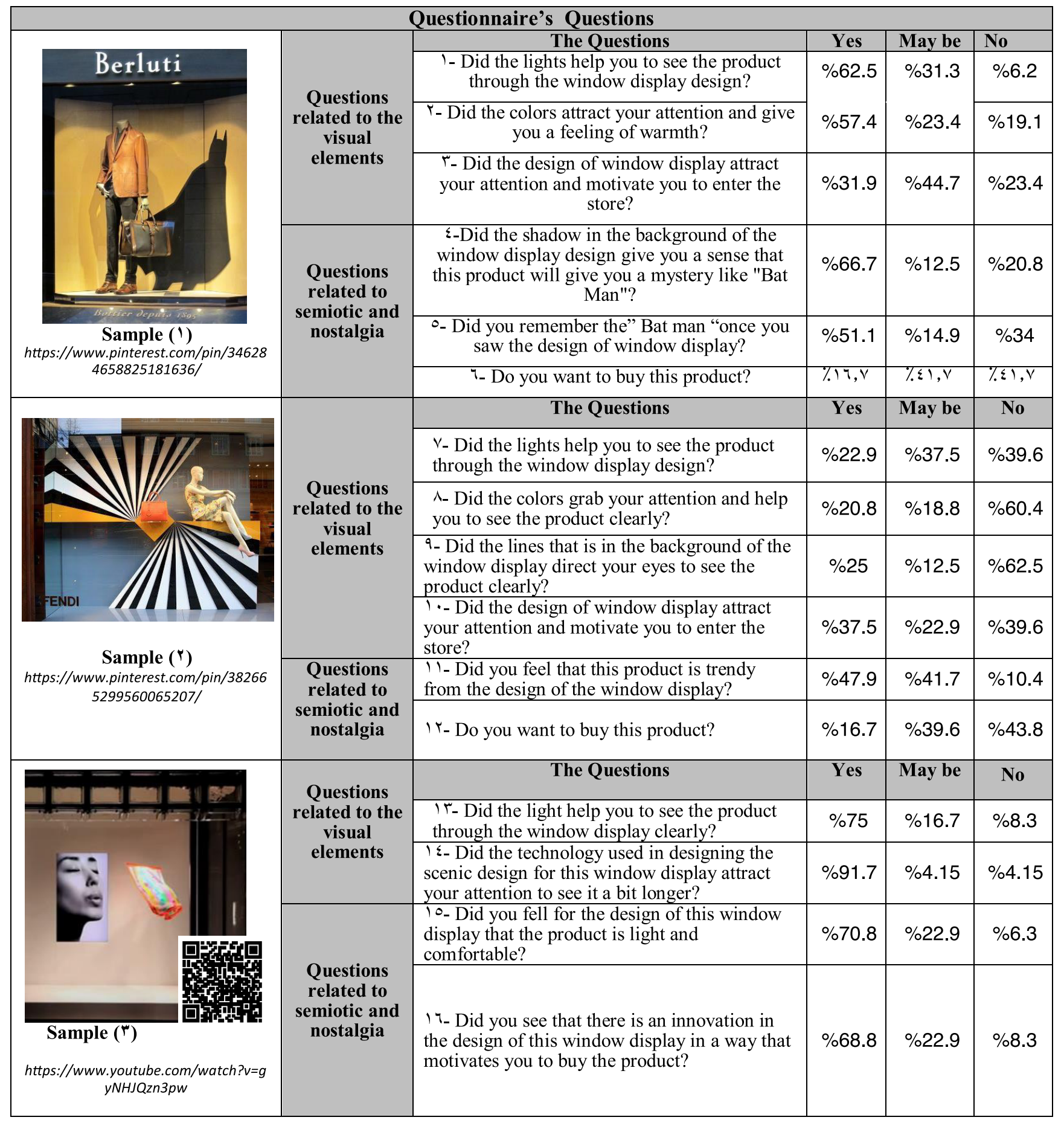




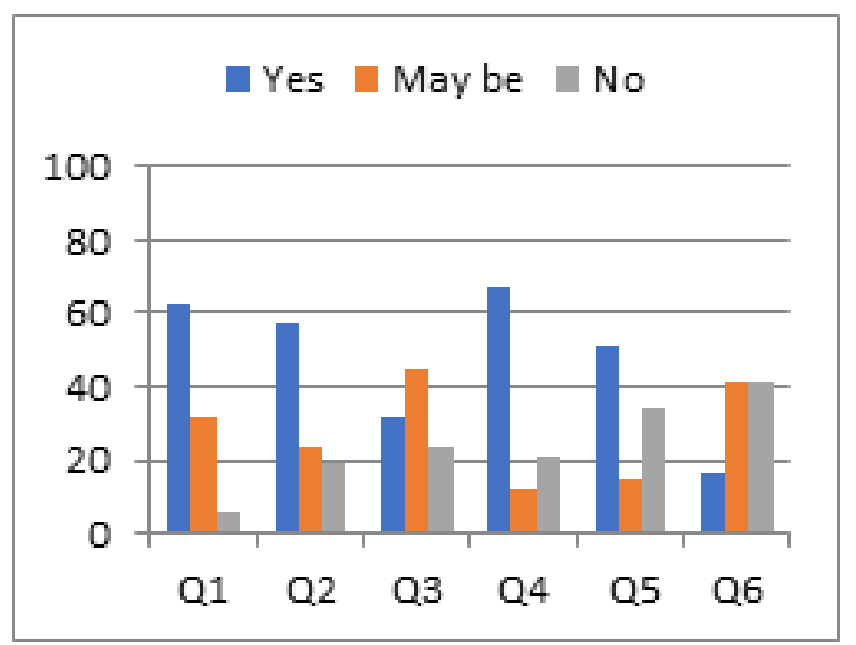

Results of sample (1)

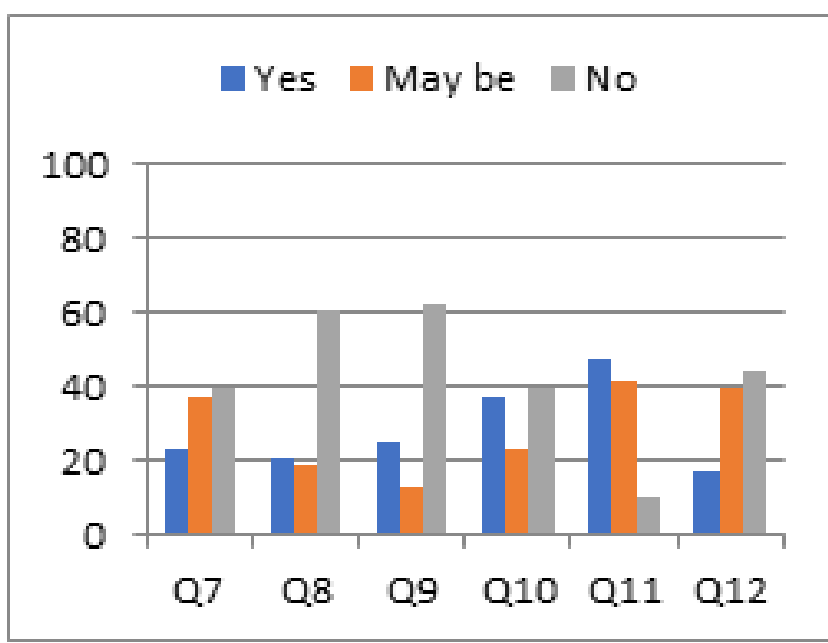

Results of sample (2)

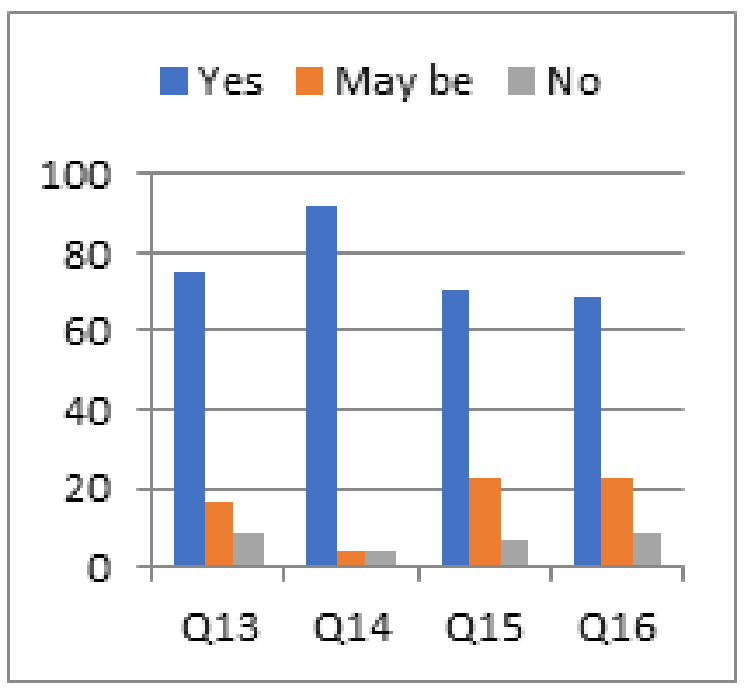

Results of sample (3)

\section{Discussion:}

From the questionnaire and analysis its results the researcher elicited the criteria of designing the scenic designs for windows display as follows

Firstly,the criteria associated with the elements of the scenic design of the windows display:

- Using the lighting to be focused on the products to highlight and emphasize them.

- It is preferable to use lighting effects to add artistic and aesthetic values to the windows display - Using colors that are in line with the overall atmosphere of the window display enhance visibility.

- Rely on innovative visual methods in the scenic designs of the windows display to attract attention.

- Baring in mind the good usage of modern technological techniques in the scenic designs of the windows display such as Hologram or motion to achieve the uniqueness and dazzle.

Secondly,the criteria related to the significances of the visual elements used in the scenic design of the windows display:

- Using the visual elements that have a positive indications to the recipients such as happiness and mystery and relate them with the offeredproducts to influence on the recipient and attract attention. - It is possible to use visual elements associated with a positive feelings toward the recipients to leave a psychological positive impact on them.

- Taking into consideration the good usage of visual elements in order to achieve the good integration between them to facilitate the delivery of associated meanings and significancesto the recipients.

\section{Results and Conclusion:}

Through the theoretical, analytical frameworks and the questionnaire the researcher got the following results:

First, Results related to the elements of the scenic designs of windows display:

- The focused lighting contributes to enhance the visibility of the products, and the usage of lighting effects contributes to garb the recipients' attention toward the design of the windows display. 
- Warm colors give a warmth feeling associated with the product displayed through the windows display, which convey a positive feelingsto the recipients.

- Using colors in the background of the scenic designs of the windows displayas the same as the color tones of the product does not give the recipients a clear visibility of the product.

- The usage of high saturation colors with black and white adds a trendyfeel to the scenic designs of the windows display

- The unintentional usage of optical illusions in the design of the scenic designs of the windows displaydoes not attract the attention and leads to dispersion.

- It's preferable to use the modern technological capabilities in the design of scenic designs of the windows display such as Hologram and lightening effects which increase the its effectiveness

Secondly, Results related to the connotations of the visual elements used in thescenic designs of windows display

- The usage of visual elements that carry a positive connotations will attract the attention of the recipients and relate the connotations of those elements with the offered products, which will strengthen the relationship between the brand and the recipients.

- The usage of visual elements associated with a positive feelings toward the recipient in the past will attract their attention and satisfy their desire to return to the past, which will convey a positive feelings associated with the products displayed in the scenic designs for windows display.

Thirdly: Results related to the design of the scenic designs of windows display:

- Following the right standards in designing the scenic designs for windows display leads to achieve the effectiveness of those windows to influence on the recipient and grabthe attention.

- Applying creativity and innovation in the scenic designs for windows displayachievesuniqueness

- Applying the good integration between visual elements leads to more efficient for the scenic designs for windows display.

\section{References:}

(1) Lamia Abdel Karim (2006) Scenography of advertising as a civilized and aesthetical trend in cities, Science and arts journal ,2(18)

(2) Walid Fayez (2012), The new trends in interior design and its impact on scenography" Faculty of applied arts ,Helwan University

(3) Alian Nicoleta, Word press organization , (2009) " The function of scenic design", Retrieved $<$ https://scenography.wordpress. com> accessed on 31/8/2019

(₹)John Munro(2015) "The lightning design", Arts a live Retrieved<http://artsalive.ca/en/eth/design/lighting.asp->

(5)<https://www.nytimes.com/2019/04/11/theater/beetlejuice-broadway-set-design.html $>$ accessed on 1/9/2019

(6)<http://paristhroughmylens.blogspot.com/2012/06/parisrouge-le-cerise.html $>$ accessed on 2/9/2019

(7)https://www.youtube.com/watch?v=47Bbrhx1VfE $>27 / 9 / 2019$.

(8) Dr. Shimaa Salah Sadek”Dynamic)Jan 2019 ) Hologram shows as a Digital Advertising Entry forCommercial Centers", International Design Journal, 1 (9)

(9) $<$ https://www.youtube.com/watch?v=37UOyi1Beow $>$ accessed on $30 / 9 / 2019$

(10)Hanan Atef, (2016), The impact of using optical illusion in designing windows display on the purchasing decision, International design journal 4 (6)

(11) $<$ https://59productions.co.uk/project/emil-and-the-detectives/>accessed on 26/9/2019

(12)<https://www.pinterest.com/pin/436286282652889436>accessed on 26/9/2019

(13)Jan Derbovena,n , Dries De Roeckb,1, Mathijs Verstraetea, ( Oct 2012 )Semiotic analysis of multi-touch interface design: The MuTable case study, International Journal of Human-Computer Studies(10)70

(14)Terry Rankin,(28Jul, 2016)How do sign syntax, semantics, and pragmatics differ between de Saussure's semiology and Peirce's semiotics?,Retrieved<https://www.quora.com/How-do-sign-syntax-semantics-and-pragmatics-differ-between-de-Saussures-semiology-and-Peirces-semiotics/answer/Terry-Rankin,> accessed on 27/9/2019

(15) Benjamin J. Hartmanna, Katja H. Brunk b, (12 Jun 2019) Nostalgia marketing and (re-)enchantment, International Journal of Research in Marketing.

(16) $<$ https://fingerlakesmtf.com/2018-season/anne-of-green-gables/> accessed on27/9/2019

(17)<https://www.pinterest.com/pin/7177680628058161/>accessed on 27/9/2019

(18)<https://www.youtube.com/watch?v=3YHH8xwV7WQ> accessed on 28/9/2019- 11:30A.M

(19)<https://www.pinterest.com/pin/346284658825181636/>accessed on 28/9/2019- 2:30P.M

(20)<https://www.pinterest.com/pin/382665299560065207/>accessedon 28/9/2019- 2:40 P.M

(21)<https://www.youtube.com/watch?v=gyNHJQzn3pw> accessed on $28 / 9 / 2019$ 